\title{
Adverse events profiles during initiation of treatment with amlodipine or hydrochlorothiazide in type 2 diabetic Nigerians with essential hypertension
}

\author{
G. B. S. Iyalomhe ${ }^{1, *}$, E. K. I. Omogbai ${ }^{2}$, A. O. Isah $^{3}$, S. I. Iyalomhe ${ }^{4}$ \\ ${ }^{1}$ Department of Pharmacology and Therapeutics, College of Medicine, Ambrose Alli University, Ekpoma, Nigeria \\ ${ }^{2}$ Department of Pharmacology and Toxicology, Faculty of Pharmacy, University of Benin, Benin City, Nigeria \\ ${ }^{3}$ Department of Internal Medicine, College of Medical Sciences, University of Benin, Benin City, Nigeria \\ ${ }^{4}$ Department of Public Health and Primary Health Care, Central Hospital, Auchi, Nigeria
}

\section{Email address:}

goddyiyalo@yahoo.com (G. B. S. Iyalomhe)

\section{To cite this article:}

G. B. S. Iyalomhe, E. K. I. Omogbai, A. O. Isah, S. I. Iyalomhe. Adverse Events Profiles during Initiation of Treatment with Amlodipine or Hydrochlorothiazide in Type 2 Diabetic Nigerians with Essential Hypertension. American Journal of Internal Medicine.

Vol. 2, No. 6, 2014, pp. 131-137. doi: 10.11648/j.ajim.20140206.16

\begin{abstract}
Background: Although, amlodipine (AML) and hydrochlorothiazide (HCZ) are recommended to initiate therapy in hypertensive patients, it has not been properly evaluated whether AML or HCZ would demonstrate a better adverse events profile. Objective: To determine whether AML or HCZ would be preferable to initiate antihypertensive treatment in type 2 diabetic Nigerians by comparing the adverse events profiles of the 2 drugs. Methods: Forty male (M) and female (F) newly diagnosed hypertensive subjects with controlled type 2 diabetic mellitus (T2DM) aged 43-68 years were randomized to AML and HCZ treatment groups of 20 patients each $(10 \mathrm{Ms}, 10 \mathrm{Fs})$, and they were treated respectively, with AML 10mg and HCZ 25mg, both drugs being given once daily for 48 weeks. Body mass index (BMI) was calculated for each subject. Blood pressure (BP), heart rate (HR), 24h urine volume were assessed at baseline and at the end of weeks 1, 3, 6, 12, 24, 36, and 48. Adverse events profiles were also recorded from week 1 through 48. Results: The drugs significantly reduced BP, though the effect of AML was significantly greater compared to that of HCZ $(\mathrm{P}<0.01)$. Diuresis was significant in HCZ group $(\mathrm{P}<0.01)$. There were 48 adverse events $(48.5 \%)$ in the AML group including weight loss and mild tachycardia. No patient had peripheral pedal edema. Fifty one events $(51.5 \%)$ occurred in HCZ group, weight loss, mild tachycardia, polyuria and myalgia/cramps being the commonest as well as impotence and visual disturbance. Conclusion: Though the two drugs appeared to be well tolerated, AML demonstrated a better BP-lowering effect and adverse events profile. Drugs that ensure adequate BP control and have the lowest possible risk for adverse events like AML, should be preferably used in diabetic Nigerian patients with essential hypertension.
\end{abstract}

Keywords: Adverse Effects of Amlodipine and Hydrochlorothiazide, Type 2 Diabetic Nigerians, Hypertension

\section{Introduction}

Worldwide, diabetes mellitus (DM) with concomitant hypertension has emerged as a major public health and clinical problem. Indeed, hypertension in patients with T2DM is a prevalent condition that is associated with substantial morbidity and mortality in Nigeria. This is because the coexistence of hypertension and diabetes in these patients dramatically and synergistically increases the risk of microvascular and macrovascular complications - a worrisome condition characterized by widespread disability, reduced capacity for work, excess premature mortality and disruption of family as well as social life among the indigenous people (1-4). Thus hypertension with DM has become a big burden in Nigeria, a country experiencing the epidemiological transition from communicable to noncommunicable diseases, a phenomenon referred to as $a$ double burden of disease (1).

Choice of an initial antihypertensive agent or agents in hypertensive patients with diabetes is difficult to define precisely because of consideration of adverse effects. For example, diuretics such as HCZ may cause polyuria, aggravating the disease condition; or induce impotence which may adversely affect adherence. AML may be associated with headache, palpitations, ankle edema or 
polyuria, with negative implications for adherence (1,5-6). In fact, recent studies reveal that one of the problems militating against adequate control of hypertension is adverse effects of medications such as orthostatic hypotension, dizziness, cough, headache, frequent urination and impotence $(1,7)$.

Indeed, some patients bewail that specific drugs are worse than hypertension itself because they feel quite well as asymptomatic hypertensives but begin to see annoying side effects with medications, their immediate benefits they cannot visualize (8). Therefore, according to Hoffman (9), the choice of an antihypertensive drug should be driven by likely benefits in an individual patient, taking into account problematic adverse effects of specific drugs, cost and concomitant diseases.

Unfortunately, there is paucity of information about adverse events regarding the use of AML and HCZ in the treatment of hypertensive type 2 diabetic patients in Nigeria. Hence, for the forgoing reasons, and based on our earlier observations (2,5$6,8,10-13)$, this randomized, open-label, prospective, twocentre study was undertaken to evaluate whether AML was superior to $\mathrm{HCZ}$ for initiating antihypertensive treatment in blacks with T2DM born and living in Nigeria, by comparing the adverse events profiles of the two drugs.

\section{Patients and Methods}

\subsection{Study Population}

The study enrolled forty $\mathrm{M}$ and $\mathrm{F}$ type 2 diabetic Nigerians with newly diagnosed essential hypertension aged 43-68 years and were attending Central Hospital and Osigbemhe Hospital both in Auchi in Edo State of Nigeria between March 2008 and March 2009. The sample size was estimated based on the number of Nigerians (14) that are believed to have hypertension with concomitant type $2 \mathrm{DM}$, and to detect a difference of 1 unit in mean change in the measured variables, between both treatment arms with a power equal to $90 \%$ using a one sample t-test at a one-sided significance level of 0.05 , requires 20 patients per group.

Eligible participants had qualifying hypertension of BP > $160 / 90$ and $\leq 180 / 120 \mathrm{mmHg}$ measured on at least 2 occasions in lying/supine, sitting and standing positions using standardized methods (15). Excluded were patients with identifiable cause of the hypertension except T2DM, clinical evidence of cerebrovascular, cardiac, renal, hepatic, gastrointestinal or endocrinologic disease except T2DM, hypersensitivity to AML and $\mathrm{HCZ}$ or related drugs, history of smoking, alcohol intake, substance abuse or mental illness. Also excluded were patients needing any concomitant medication (apart from oral antidiabetic drugs) eg digitalis, non-steroidal anti-inflammatory drugs, psychotropic drugs, monoamine oxidase inhibitors or oral contraceptives, that may interact with the trial drugs and pregnant or lactating Fs.

Controls comprised the parallel age and sex-matched hypertensives on HCZ. The research protocol was reviewed and approved by the Ethics Committees of Irrua Specialist Teaching Hospital Irrua, Nigeria (Ambrose Alli University
College of Medicine Teaching Hospital) and Central Hospital Auchi, Nigeria. After suitable explanation of the study protocol in lay language, all literate patients gave informed written consent and the illiterates thumb-printed the consent form before the beginning of the study.

\subsection{Study Design}

\subsubsection{Questionnaire}

Subjects were examined by a standardized pre-tested questionnaire seeking information on demographic data, the history of hypertension, DM, current drugs if any, educational and social status, dietary habits, smoking and alcohol intake, etc. The 40 patients were randomized to AML and HCZ groups each comprising 20 patients (10 Ms $+10 \mathrm{Fs})$ using computer program-generated random numbers. Diabetes was treated and controlled well in 32 patients with oral hypoglycaemic agents viz a sulfonylurea (glibenclamide $5 \mathrm{mg}$ once daily) and a biguanide (metformin $500 \mathrm{mg}$ once or twice daily) and in 8 patients with gliclazide $80 \mathrm{mg}$ once or twice daily.

\subsubsection{Measurements}

Heights (m), weights (wt) (kg), BP (mmHg), pulse (bpm), HR (bpm), urine volume $(\mathrm{ml} / 24 \mathrm{~h})$, were measured as follows:

A stadiometer scale (Seca model, UK) was used for measuring height, with no shoes on; and a beam balance (Hackman, UK) was used to measure wt while on light clothing. BMI was computed as wt divided by height squared. SBP and DBP were measured with a standard mercury sphygmomanometer (Riester Diplomat Presameter, Germany) using standardized methods (15), always between 8am and $10 \mathrm{am}$. Radial pulse was taken at both hands at the beginning and then at the right hand at every visit. HR was evaluated using the stethoscope diaphragm at the apex beat at every visit. The volume of $24 \mathrm{~h}$ urine collected was measured with a measuring cylinder and recorded. The need to carefully collect all urine passed between Sunday 7am and Monday 7 am on evaluation days was well emphasized.

\subsubsection{Pharmacotherapy Intervention}

Patients in AML group were treated initially with AML 5 $\mathrm{mg}$ and the dose was doubled after 6 weeks if BP was not controlled while in $\mathrm{HCZ}$ group patients were treated with HCZ $25 \mathrm{mg}$, both medications being administered once daily. The outpatient treatment lasted 48 weeks. The patients were monitored closely and outcome measures evaluated at baseline before treatment and at the end of weeks 1, 3, 6, 12, 24, 36 and 48. Unequivocal patient identification was possible via a patient identification list consisting of the patient number, first name and surname.

The study medications AML and HCZ are licensed for long-term treatment of hypertension so that dangerous side effects due to the medicaments were not to be expected. AML 5mg and $10 \mathrm{mg}$ tablets $\left(\right.$ Amlovar $^{\mathrm{R}}$ ), were donated by Neimeth International Pharmaceuticals Ikeja, Nigeria: NAFDAC Reg No A4-0333; Manufacturing Date 07-2007 and Expiry Date 07-2010. HCZ 25mg tablets (Esidrex ${ }^{\mathrm{R}}$ ) were 
donated by Novartis Pharma SAS Nigerian Representative, NAFDAC Reg No OL-3705, Manufacturing Date 08-2007 and Expiry Date 08-2010.

Response to therapy was defined as a decrease in the mean trough sitting SBP and DBP of $10 \mathrm{mmHg}$ or a drop to $<90$ $\mathrm{mmHg}$ with reduction of $>5 \mathrm{mmHg}$. BP was regarded as controlled if the DBP was $<80 \mathrm{mmHg}$ and SBP $<130$ $\mathrm{mmHg}$. The effects of treatment on the various variables (except height) were assessed by comparing the values at each visit with the pretreatment baseline values.

\subsubsection{Course of Study and Methods for Recording Efficacy and Safety}

All patients were advised to maintain their usual diet (weight-maintaining no-salt-added diet) and regular physical activity but to avoid undue stress throughout the duration of the study. They were instructed to take their drugs every morning. Each patient was observed for about 2 hours after taking medication drug for the first time. Adherence in respect of intake of medication was encouraged by interviewing patients through phone calls, sporadic visits, pill counts outside the view of patients as well as urine volume measurements. To preclude white-coat effect, observer bias and to accurately assess the efficacy of the drugs, patients were followed up repeatedly at weeks $1,3,6,12,24,36$, and 48. At each visit, volunteered or spontaneous report of adverse events were assessed for severity and association with treatment; and the attending physicians/investigators also recorded any adverse events they observed themselves or elicited from the patient through careful interrogation like "How do you feel?" No patient withdrew from the study because of adverse events.

\subsubsection{Data Analysis}

All data are presented as mean \pm SEM or mean \pm SD (for age, height and weight) using the Proc ANOVA of SAS (2004). Where significant differences were noticed, mean separation was carried out using Duncan Multiple Range Test. Correlation between two sets of variables was determined using Spearman's rank correlation. $P<0.05$ was regarded as significant in all cases.

\section{Results}

As shown in Table 1, 20 patients were randomized to the AML and HCZ groups and each group was divided into 2 subgroups of $10 \mathrm{M}$ and $10 \mathrm{~F}$. At baseline, no significant difference was detected in the means of ages, BMIs, and SBPs/DBPs. However, subjects were relatively younger with high BMIs and significant (stage 2) hypertension. No patient was lost to follow-up throughout the study, perhaps because of the free treatment they were enjoying.

The effects of treatment drugs on SBPs and DBPs in the trial subjects are presented in Table 2. The duration of treatment effect on the variables was significant $(P<0.0001)$ because at week 6, while on AML 5mg, 2 patients (2M) had their DBP $<90 \mathrm{mmHg}$ and at week 12 while all the patients were on AML $10 \mathrm{mg}$, 5 patients $(4 \mathrm{M}+1 \mathrm{~F})$ had DBP $<90$ $\mathrm{mmHg}$. At week 48,11 patients $(3 \mathrm{M}+7 \mathrm{~F})$ had their DBP < $90 \mathrm{mmHg}$ whereas 6 patients $(3 \mathrm{M}+3 \mathrm{~F})$ had $\mathrm{BP}<130 / 80$ $\mathrm{mmHg}$. For HCZ group, no patient had DBP $<90 \mathrm{mmHg}$ at week 6; at week 12, 4 patients $(1 \mathrm{M}+3 \mathrm{~F})$ had DBP $<90$ $\mathrm{mmHg}$ and at week 48,4 patients $(2 \mathrm{M}+2 \mathrm{~F})$ had their SBP/DBP $<130 / 80 \mathrm{mmHg}$. Overall, the mean $\mathrm{M}$ vs $\mathrm{F}$ SBP/DBP decrease from baseline was $27.0 / 17.5$ vs $29.5 / 20.0$ $\mathrm{mmHg}$ for AML group and 23.5/17.5 vs 22.0/16.5 $\mathrm{mmHg}$ for HCZ group.

Treatment, time or gender effect did not significantly affect the HR (Table 3). The effects of treatment drugs on $24 \mathrm{~h}$ urine volume are presented in Table 4 . Treatment and gender effects were not significantly different in the groups. However, the time-dependent effect was significant $(P<$ 0.001 ) because AML caused a maximum mean $\mathrm{M}$ vs $\mathrm{F} \%$ diuresis of $3.6 \mathrm{v} 5.1$ at week 12 and $\mathrm{HCZ} 8.2$ vs 6.9, respectively at week 3 . Diuresis decreased soon after towards baseline particularly in HCZ group. Urine volume was positively correlated with age $(r=0.2003, P=0.0003)$.

Table 1. Demographic characteristics and baseline blood pressures of hypertensive diabetic subjects $(N=20[10 M+10 F]$ per group $)$

\begin{tabular}{|c|c|c|c|c|c|}
\hline \multirow{2}{*}{ Group } & \multirow{2}{*}{ Characteristics } & \multicolumn{2}{|l|}{ Male } & \multicolumn{2}{|l|}{ Female } \\
\hline & & Range & Mean \pm SD/SEM ${ }^{*}$ & Range & Mean \pm SD/SEM ${ }^{*}$ \\
\hline \multirow{6}{*}{ AML } & Age (yrs) & $46-61$ & $53.90 \pm 5.04$ & $45-62$ & $53.10 \pm 5.38$ \\
\hline & Height (m) & $1.59-1.73$ & $1.66 \pm 0.04$ & $1.58-1.71$ & $1.64 \pm 0.05$ \\
\hline & Weight (kg) & $74-90$ & $83.20 \pm 5.13$ & $72-89$ & $80.0 \pm 4.71$ \\
\hline & BMI. $\left(\mathrm{kg} / \mathrm{m}^{2}\right)$ & $29.37-30.10$ & $30.25 \pm 0.24$ & $28.92-30.48$ & $29.00 \pm 0.70$ \\
\hline & $\mathrm{SBP}(\mathrm{mm} \mathrm{Hg})$ & $150-180$ & $164.50 \pm 3.76^{*}$ & $155-180$ & $166.50 \pm 2.24^{*}$ \\
\hline & $\mathrm{DBP}(\mathrm{mm} \mathrm{Hg})$ & $100-115$ & $104.50 \pm 1.89^{*}$ & 100.110 & $105.00 \pm 1.57^{*}$ \\
\hline \multirow{6}{*}{$\mathrm{HCZ}$} & Age (yrs) & $45-65$ & $52.40 \pm 6.75$ & $43-68$ & $54.50 \pm 7.73$ \\
\hline & Height (m) & $1.62-1.74$ & $1.68 \pm 0.04$ & $1.58-1.70$ & $1.64 \pm 0.03$ \\
\hline & Weight (kg) & $77-90$ & $84.51 \pm 4.32$ & $63-86$ & $76.44 \pm 6.54$ \\
\hline & BMI $\left(\mathrm{kg} / \mathrm{m}^{2}\right)$ & $29.39-30.00$ & $29.96 \pm 0.19$ & $26.30-29.76$ & $27.50 \pm 0.53$ \\
\hline & $\mathrm{SBP}(\mathrm{mm} \mathrm{Hg})$ & $98-180$ & $162.50 \pm 3.71^{*}$ & $150-180$ & $162.00 \pm 2.62^{*}$ \\
\hline & DBP(mm Hg) & $90-115$ & $104.50 \pm 1.89^{*}$ & $100-115$ & $102.50 \pm 2.71^{*}$ \\
\hline
\end{tabular}

Characteristics and blood pressures are not significantly different between the groups and hypertensives are relatively younger with high BMIs; AML, Amlodipine; HCZ, Hydrochlorothiazide; BMI, Body mass index; SBP, Systolic blood pressure; DBP, Diastolic blood pressure; M, male; F, female;

*, Standard error of mean 
Table 2. Effects of initiating treatment with AML or HCZ for 48 weeks on BP ( $\mathrm{mmHg}$ ) in type 2 hypertensive diabetic subjects

\begin{tabular}{|c|c|c|c|c|c|c|}
\hline \multirow{2}{*}{ Week } & \multirow{2}{*}{ BP } & \multicolumn{2}{|c|}{ Treatment Subgroups (Male) } & \multicolumn{2}{|c|}{ Treatment Subgroups (Female) } & \multirow{2}{*}{ Gender Effect } \\
\hline & & AML & HCZ & AML & $\mathrm{HCZ}$ & \\
\hline \multirow{2}{*}{0} & SBP & $164.50 \pm 3.76$ & $165.00 \pm 3.71$ & $166.50 \pm 2.24$ & $162.00 \pm 3.59$ & \\
\hline & DBP & $103.60 \pm 1.89$ & $104.50 \pm 1.89$ & $104.50 \pm 1.57$ & $102.50 \pm 2.71$ & \\
\hline \multirow{2}{*}{1} & SBP & $161.50 \pm 3.17$ & $162.00 \pm 3.51$ & $163.00 \pm 2.49$ & $160.00 \pm 3.33$ & \\
\hline & DBP & $100.50 \pm 1.17$ & $102.00 \pm 2.49$ & $102.00 \pm 1.33$ & $100.00 \pm 2.69$ & \\
\hline \multirow{2}{*}{3} & SBP & $158.50 \pm 3.58_{\mathrm{A}}$ & $157.50 \pm 3.75_{\mathrm{A}}$ & $161.50 \pm 1.98_{\mathrm{A}}$ & $156.50 \pm 2.48_{\mathrm{A}}$ & \\
\hline & DBP & $99.00 \pm 0.69_{\mathrm{A}}$ & $97.50 \pm 2.01_{\mathrm{A}}$ & $98.00 \pm 1.33_{\mathrm{A}}$ & $98.00 \pm 2.49_{\mathrm{A}}$ & \\
\hline \multirow{2}{*}{6} & SBP & $151.50 \pm 2.99_{\mathrm{B}}$ & $152.50 \pm 2.81_{\mathrm{B}}$ & $156.00 \pm 2.21_{\mathrm{B}}$ & $151.00 \pm 3.15_{\mathrm{B}}$ & \\
\hline & DBP & $90.00 \pm 2.11_{\mathrm{B}}$ & $94.00 \pm 1.63_{\mathrm{A}}$ & $93.00 \pm 1.50_{\mathrm{B}}$ & $92.00 \pm 1.53_{\mathrm{B}}$ & \\
\hline \multirow{2}{*}{12} & SBP & $146.50 \pm 2.36_{\mathrm{C}}$ & $148.50 \pm 2.99_{\mathrm{C}}$ & $152.00 \pm 1.70_{\mathrm{B}}$ & $146.50 \pm 2.79_{\mathrm{C}}$ & $0.320^{\mathrm{NS}}$ \\
\hline & DBP & $87.50 \pm 1.54_{\mathrm{C}}$ & $87.50 \pm 1.17_{\mathrm{B}}$ & $90.50 \pm 1.17_{\mathrm{B}}$ & $88.00 \pm 1.53_{\mathrm{C}}$ & $0.877^{\mathrm{NS}}$ \\
\hline \multirow{2}{*}{24} & SBP & $142.50 \pm 2.14_{\mathrm{C}}$ & $146.50 \pm 3.34_{\mathrm{C}}$ & $145.00 \pm 2.17_{\mathrm{C}}$ & $145.00 \pm 3.07_{\mathrm{C}}$ & \\
\hline & DBP & $86.50 \pm 1.50_{\mathrm{B}}$ & $87.00 \pm 1.34_{\mathrm{B}}$ & $89.50 \pm 0.50_{\mathrm{C}}$ & $87.50 \pm 1.71_{\mathrm{C}}$ & \\
\hline \multirow{2}{*}{36} & SBP & $142.00 \pm 2.00_{\mathrm{C}}$ & $143.00 \pm 3.59_{\mathrm{D}}$ & $141.00 \pm 1.94_{\mathrm{D}}$ & $142.00 \pm 3.82_{\mathrm{D}}$ & \\
\hline & DBP & $86.00 \pm 1.63_{\mathrm{C}}$ & $87.00 \pm 1.53_{\mathrm{B}}$ & $88.00 \pm 1.33_{\mathrm{C}}$ & $86.00 \pm 1.80_{\mathrm{C}}$ & \\
\hline \multirow{2}{*}{48} & SBP & $137.50 \pm 2.61_{\mathrm{D}}$ & $141.50 \pm 3.42_{D}$ & $137.00 \pm 2.26_{\mathrm{D}}$ & $140.00 \pm 3.58_{\mathrm{D}}$ & \\
\hline & DBP & $86.00 \pm 1.63_{\mathrm{C}}$ & $87.00 \pm 1.53_{\mathrm{B}}$ & $84.50 \pm 1.57 \mathrm{D}$ & $86.00 \pm 1.80_{\mathrm{C}}$ & \\
\hline
\end{tabular}

Significant differences within columns are indicated by ABCD $(\mathrm{P}<0.05)$ : There are significant time-dependent reductions in BP in groups; SBP, Systolic blood pressure; DBP, Diastolic blood pressure; AML, amlodipine; HCZ, hydrochlorothiazide; NS, not significant; ( $\mathrm{N}=10$ per subgroup)

Table 3. Effects of initiating treatment with AML or HCZ for 48 weeks on heart rate (bpm) in type 2 hypertensive diabetic subjects

\begin{tabular}{lllll}
\hline \multirow{2}{*}{ Week } & \multicolumn{2}{l}{ Treatment Subgroups (Male) } & \multicolumn{2}{l}{ Treatment Subgroups (Female) } \\
\cline { 2 - 5 } & AML & HCZ & AML & HCZ \\
\hline 0 & $74.00 \pm 1.37$ & $73.40 \pm 0.99$ & $72.20 \pm 1.05$ & $74.40 \pm 1.11$ \\
1 & $74.20 \pm 1.44$ & $72.80 \pm 1.05$ & $72.20 \pm 1.05$ & $74.20 \pm 1.29$ \\
3 & $75.00 \pm 1.27$ & $73.80 \pm 1.05$ & $73.20 \pm 0.95$ & $74.40 \pm 1.11$ \\
6 & $76.20 \pm 1.47$ & $73.40 \pm 1.07$ & $74.20 \pm 0.87$ & $74.40 \pm 1.11$ \\
12 & $76.40 \pm 1.39$ & $73.40 \pm 1.08$ & $74.20 \pm 0.87$ & $74.40 \pm 1.11$ \\
24 & $76.40 \pm 1.45$ & $73.20 \pm 1.12$ & $74.00 \pm 0.89$ & $74.80 \pm 1.08$ \\
36 & $75.80 \pm 1.28$ & $73.20 \pm 1.12$ & $74.00 \pm 0.89$ & $74.80 \pm 1.08$ \\
48 & $75.80 \pm 1.28$ & $73.20 \pm 1.12$ & $74.00 \pm 0.89$ & $74.80 \pm 1.08$ \\
\hline
\end{tabular}

Heart rate is neither significantly affected by treatment nor by time; other abbreviations are as used in Table 2

Table 4. Effects of initiating treatment with AML or HCZ for 48 weeks on $24 \mathrm{~h}$ urine volume ( $\mathrm{ml}$ ) in hypertensive diabetic subjects

\begin{tabular}{|c|c|c|c|c|c|}
\hline \multirow{2}{*}{ Week } & \multicolumn{2}{|c|}{ Treatment Subgroups (Male) } & \multicolumn{2}{|c|}{ Treatment Subgroups (Female) } & \multirow{2}{*}{ Gender Effec } \\
\hline & AML & HCZ & AML & HCZ & \\
\hline 0 & $1483.00 \pm 27.21$ & $1472.00 \pm 33.56$ & $1460.00 \pm 22.31$ & $1489.00 \pm 26.10$ & \multirow{8}{*}{$0.898^{\mathrm{NS}}$} \\
\hline 1 & $1501.00 \pm 27.67$ & $1565.00 \pm 36.06$ & $1485.00 \pm 21.92^{\mathrm{b}}$ & $1567.00 \pm 30.55^{\mathrm{a}}$ & \\
\hline 3 & $1521.00 \pm 27.10$ & $1593.00 \pm 27.21_{\mathrm{A}}$ & $1516.00 \pm 22.76$ & $1591.00 \pm 30.60_{\mathrm{A}}$ & \\
\hline 6 & $1536.00 \pm 26.41$ & $1520.00 \pm 28.40$ & $1530.00 \pm 22.80$ & $1536.00 \pm 27.01$ & \\
\hline 12 & $1538.00 \pm 26.05$ & $1498.00 \pm 32.28$ & $1534.00 \pm 21.09_{\mathrm{A}}$ & $1517.00 \pm 25.12$ & \\
\hline 24 & $1525.00 \pm 25.70$ & $1492.00 \pm 32.52$ & $1516.00 \pm 22.57$ & $1506.00 \pm 25.48$ & \\
\hline 36 & $1506.00 \pm 27.86$ & $1487.00 \pm 33.67$ & $1488.00 \pm 22.99$ & $1504.00 \pm 25.43$ & \\
\hline 48 & $1504.00 \pm 28.10$ & $1483.00 \pm 33.13$ & $1466.00 \pm 22.12$ & $1498.00 \pm 27.28$ & \\
\hline
\end{tabular}

Significant differences within columns are indicated by $\mathrm{AB}$ and within rows by $\mathrm{ab}(\mathrm{P}<0.05)$ : There is significant timedependent diuresis that peaked at weeks 12 and 3 in AML and HCZ subgroups, respectively; other abbreviations are as used in Table 2. 
Table 5. Adverse events profiles during initiation of antihypertensive therapy with AML or HCZ in diabetic subjects for 48 weeks

\begin{tabular}{|c|c|c|c|c|}
\hline \multirow{3}{*}{ Adverse events } & \multicolumn{2}{|c|}{ Amlodipine* } & \multicolumn{2}{|c|}{ Hydrochlorothiazide*** } \\
\hline & \multicolumn{2}{|c|}{ No. of Patients } & \multicolumn{2}{|c|}{ No. of Patients } \\
\hline & Male & Female & Male & Female \\
\hline Polyuria & 2 & - & 4 & 2 \\
\hline Headache & 1 & 2 & 2 & - \\
\hline Dizziness & - & - & 1 & 1 \\
\hline Tachycardia & 10 & 8 & 4 & 2 \\
\hline Myalgias/cramps & 1 & 2 & 2 & 4 \\
\hline Nausea & - & - & 1 & 2 \\
\hline Peripheral neuropathy/paraesthesia & 2 & - & 3 & - \\
\hline Weight reduction & 10 & 10 & 10 & 10 \\
\hline Others & - & - & $2^{\mathrm{s}}$ & $1^{\mathbf{P}}$ \\
\hline Total & 26 & 22 & 29 & 21 \\
\hline
\end{tabular}

( $\mathrm{N}=20$ per group) $\quad \mathrm{S}$, Impotence; $\mathrm{P}$, Visual Disturbance

*2 patients had $>1$ event $\quad * * 3$ patients had $>1$ event

\section{Discussion}

Expectedly, AML and $\mathrm{HCZ}$ were well tolerated and no patient withdrew because of adverse events which were mild, comparable and consistent with the safety profile of each drug. Relatively however, more patients in HCZ group $(51.5 \%)$ had drug-related adverse experiences compared to AML group (48.5\%). In particular and in contrast with some other reports (16-17), it is remarkable that no patient in the AML group developed pedal edema. This may be explained by the fact that the patients were salt-sensitive and had adequate natriuresis and diuresis (2,5,10-13).

The occurrence of impotence or erectile dysfunction (ED) in 2 patients in the HCZ group in sexually-active Nigerian men constitutes a psychological insult unmitigated by no extenuating circumstance because of the high premium placed on sex and procreation by Nigerians. Although there is little trial-based evidence to indicate which drugs are more likely to cause this side effect, in general, thiazide diuretics and beta blockers seem to cause ED more often (18-19). All the same hypertension, being a predictor of ED, constitutes further evidence supporting a link between the pathogenesis of atherosclerotic disease and ED. In the Treatment of Mild Hypertension Study (TOMHS), the incidence of ED was $14.4 \%(18,20)$. This adverse effect may have a negative impact on medication adherence.

The question of nephrotoxicity of long-term diuretic therapy continues to surface and the association between renal cell carcinoma and diuretic therapy remains a concern because the renal tubular cell ie the cell that turns cancerous, is also the main target of the diuretic pharmacological effect (21-24). Because diuretic-associated carcinogenicity seemed to be cumulative in some studies, it may be yet another reason not to expose young patients, particularly those with stage 1 hypertension, to years and decades of thiazide therapy with the attendant risk of development of new-onset $\mathrm{DM}$ and dyslipidaema when there are safer drugs like AML that may not engender such risks. However, the issue of carcinogenicity with hypertension and/or antihypertensive therapy is not well understood, and hence hasty conclusions should be avoided.
The adherence of patients to medication depends on multiple factors, including economic costs of the drugs. Previously, the Guideline Committees endorsed thiazides as first-line agents given the actual cost of medication. However, such an approach does not take into account the efficacy and effectiveness of medication. An ideal cost-effectiveness analysis should consider the relative effectiveness of different drugs on clinical outcomes, the direct and indirect cost associated with long-term complications of the medications (such as development of or aggravation of DM), and the actual cost of the drugs. Such a formal costeffectiveness analysis was performed by the National Institute for Health and Clinical Excellence (NICE) London. On the basis of their health-economic model, they concluded that for 65-year old men and women with an annual cardiovascular risk of $2 \%$, heart failure risk of $1 \%$ and DM risk of $1.1 \%$, the most cost-effective initial drug for treating hypertension was a calcium channel blocker (CCB) $(19,25)$. Although it has been argued in Antihypertensive and Lipid Lowering Treatment to Prevent Heart Attack Trial (ALLHAT) study that diuretics remain a cornerstone in the therapeutic arsenal and that their benefits distinctly outweigh their lowgrade negative metabolic adverse effects, it is unfortunate to continue to insist on their being used as first-line agents in blacks given that till date, not only diuretics but also CCBs remain the only antihypertensive drugs that have been shown to reduce morbidity and mortality against placebo in hypertension (19).

\section{Conclusion}

Drug-related adverse experiences, which were mild, were relatively more common with $\mathrm{HCZ}$ treatments indicating that AML has superior tolerability. Pedal edema was not observed with AML treatment, suggesting that the drug may be particularly effective in Nigerians. ED was a psychological insult experienced with HCZ treatment in some patients and this may have negative implications for medication adherence. The trade-off of lowering BP, especially in the young hypertensive patients who may be exposed to HCZ for a long time, at the expense of compromising the control of $\mathrm{DM}$ is unacceptable, given that there are alternative safer and 
equally efficacious antihypertensive drugs like AML that do not worsen DM or cause hyperlipidaemia. Drugs that ensure adequate BP control and have the lowest possible risks for adverse events like AML should be used in black T2DM patients with essential hypertension. This is the first study in Nigeria that has confirmed the results of previous studies done elsewhere that AML is more effective and safer than $\mathrm{HCZ}$ as initial treatment in diabetic hypertensive Nigerians.

However, because of the small number of patients studied, caution should be exercised in interpreting our data or extrapolating the findings to hypertensive diabetic black patients in general.

\section{Acknowledgments}

The authors appreciate gratefully the Managements of the hospitals and patients used for this study as well as Neimeth International Pharmaceuticals, Nigeria for donation of amlodipine $\left(\right.$ Amlovar $\left.^{\mathrm{R}}\right)$ tablets and the Nigerian Representative of Novartis Pharma SAS France for donation of hydrochlorothiazide $\left(\right.$ Esidrex $^{\mathrm{R}}$ ) tablets for the study.

\section{References}

[1] V. Mohan, Y.K. Seedat, and R. Pradeepa, "The rising burden of diabetes and hypertension in Southeast Asia and African regions: need for effective strategies for prevention and control in primary health care settings", Int. J. Hypertens., vol. 2013, Article ID 409083, 14 pages. http://dx.doi.org/10.115/2013/409083.

[2] G.B.S. Iyalomhe, E.K.I. Omogbai, A.O. Isah, S.I. Iyalomhe, O. Okhiai, F.L. Dada, and O.O.B. Iyalomhe, "Comparison of the long-term efficacy and some metabolic effects of initiating therapy with amlodipine or hydrochlorothiazide in hypertensive type 2 diabetic Nigerians". Int. J. Health Sci. Res. vol.4, No.7, pp. 149-161, 2014.

[3] O.O. Ogunleye, S.O. Ogundele, J.O. Akinyemi, and A.O. Ogbera, "Clustering of hypertension, diabetes mellitus and dyslipidemia in a Nigerian population: a cross sectional study”. Afr. J. Med. Med. Sci., vol.41, pp.191-195, 2012.

[4] B.C. Unadike, A. Eregie, and A.E. Ohwovoriole, "Prevalence of hypertension amongst persons with diabetes mellitus in Benin City, Nigeria”. Nig. J. Clin. Pract., vol.14, pp.300-302, 2011.

[5] G.B.S. Iyalomhe, E.K.I. Omogbai, and O.O.B. Iyalomhe, "Long-term electrolyte effects during initiation of antihypertensive therapy with amlodipine or hydrochlorothiazide in diabetic Nigerians", Am. J. Med. Sci. Med., vol.1, No3, pp.1-7, 2013.

[6] G.B.S. Iyalomhe, "Compliance to antihypertensive therapy", Nig. Clin. Rev. J., vol.63, pp.12-16, 2007.

[7] D.A. Oke, and E.O. Bandele, "Misconceptions of hypertension", J. Nat. Med. Assoc., vol.96, pp.1221-1224, 2004.

[8] G.B.S. Iyalomhe, and S.I. Iyalomhe, "Hypertension-related knowledge, attitudes and life-style practices among hypertensive patients in a sub-urban Nigerian community", J.
Public Health Epidemiol., vol.2, No.4, pp.71-77, July 2010.

[9] B.B. Hoffman, "Therapy of hypertension”, in Goodman and Gilman's The pharmacological Basis of Therapeutics, $11^{\text {th }}$ ed., J. G. Hardman and L.E. Limbird, Eds. New York: McGraw Hill, 2006, pp.845-868.

[10] N.L. Benowitz, "Antihypertensive agents", in Basic and Clinical Pharmacology $11^{\text {th }}$ ed, B.G. Katzung Ed., Boston: McGraw Hill Lange, 2009, pp: 167-189.

[11] G.B.S. Iyalomhe, E.K.I. Omogbai, A.O. Isah, O.O.B. Iyalomhe, F.L. Dada, and S.I. Iyalomhe, "Effects of initiating therapy with amlodipine or hydrochlorothiazide on creatinine clearance in hypertensive Nigerians with type 2 diabetes mellitus", Br. Biotech. J. vol.3, No.1, pp.79-89, 2013.

[12] G.B.S. Iyalomhe, E.K.I. Omogbai, A.O. Isah, O.O.B. Iyalomhe, F.L. Dada, and S.I. Iyalomhe, "Efficacy of initiating therapy with amlodipine and hydrochlorothiazide or their combination in hypertensive Nigerians". Clin. Exper. Hypertens. Early online 1-8 2013; DOI: 10.3109/10641963.776570.

[13] G.B.S. Iyalomhe, E.K.I. Omogbai, and R.I. Ozolua "Antihypertensive and biochemical effects of hydrochlorothiazide and furosemide in hypertensive Nigerians”, J. Med. Sci., vol.7, No.6, pp.977-983, Aug 2007.

[14] O.O. Akinkugbe, "Current epidemiology of hypertension in Nigeria”, Arch. Ibadan Med., vol.1, pp.3-5, 2003.

[15] T.G. Pickering, J.E. Hall, L.J. Appel, B.E. Falkner, J. Graves, M.N Hill, D.W. Jones, T. Kurtz, S.G. Sheps, and E.J. Rocella, "Recommendations for blood pressure measurement in humans and experimental animals part1. Blood pressure measurement in humans: a statement for professionals from the Subcommittee of Professional and Public Education of the American Heart Association Council on High Blood Pressure Research”, Circulation., vol.III, pp.697-716, 2005.

[16] T. Tejada, A. Fornomi, O. Lenz, and B.J. Materson, "Combination therapy with renin-angiotensin system blockers: will amlodipine replace hydrochlorothiazide?", Curr. Hypertens. Rep., vol.9, pp.284-290, 2007.

[17] ALLHAT Collaborative Research Group, "Outcomes in hypertensive black and non-black patients treated with chlorthalidone, amlodipine and lisinopril". JAMA, vol.293, No.13, pp.1595-1598, 2005.

[18] D.P. Mikhailidis, M.A. Khan, H.J. Milioris, and R.H. Morgan, "The treatment of hypertension in patients with erectile dysfunction", Curr. Med. Res. Opin., vol.16, No.51, pp.531536, 2000.

[19] F.H. Messerli, S. Bangalore, and S. Julius, "Risk / benefit assessment of $\beta$-blockers and diuretics precludes their use for first-line therapy in hypertension", Circulation, vol.117, pp.2706-2715, 2008.

[20] R.H. Grim, G.A. Grandits, R.J. Prineas, R.H. McDonald, C.E. Lewis, and J.M. Flack for the TOMHS Research Group, "Long-term effects on sexual function of five antihypertensive drugs and nutrition hygienic treatment in hypertensive men and women. Treatment of Mild Hypertension Study (TOMHS)", Hypertens., vol.29, pp.8-14, 1997.

[21] E. Grossman, F.H. Messerli, and V. Goldbourt, "Does diuretic therapy increase the risk of renal cell carcinoma?", Am. J. Cardiol., vol.83, pp.1090-1093, 1997. 
[22] S. Reungjul, H. Hu, W. Mu, CA. Roncal, B.P. Croker, J.M. Pater, T. Nakagawa, T. Srinivas, K. Byer, J. Simoni, D. Wesson, V. Sitprija, and R.J. Johnson, "Thiazide-induced subtle renal injury not observed in states of equivalent hypokalaemia”, Kidney Int., vol.72, pp.1483-1492, 2007.

[23] B.H. Rovin, and L.A. Hebert, "Thiazide diuretic monotherapy for hypertension: diuretic's dark side just got darker", Kidney Int. vol.72, pp.1423-1426, 2007.
[24] D.H. Ellison, and J. Loffing, "Thiazide effects and adverse effects: insight from molecular genetics", Hypertens., vol.54, pp.196-204, 2009.

[25] Royal College of Physicians, National Collaborating Centre for Chronic Conditions. "Hypertension: management of hypertension in adults in primary care, partial update", London, UK, 2006. 